\title{
Myeloid and plasmacytoid dendritic cell combined vaccines loaded with heat-treated tumor cell lysates enhance antitumor activity in murine lung cancer
}

\author{
HUIGUO CHEN ${ }^{1 *}$, JIANFENG TAN $^{2 *}$, XIAOJUN LI ${ }^{1 *}$, HUI LI $^{3}$, WEIBIN WU ${ }^{1}$, \\ YONGHUI WU ${ }^{1}$, JIAN ZHANG ${ }^{1}$ and LIJIA GU ${ }^{1}$
}

${ }^{1}$ Department of Cardiothoracic Surgery, The Third Affiliated Hospital, Sun Yat-sen University, Tianhe, Guangzhou,

Guangdong 510630; ${ }^{2}$ Department of Thoracic Surgery, ShenZhen Hospital of Southern Medical University, Bao'an, ShenZhen, Guangdong 518000; ${ }^{3}$ Department of Cardiothoracic Surgery, ZhuJiang Hospital of Southern Medical University, Haizhu, Guangzhou, Guangdong 510280, P.R. China

Received February 26, 2020; Accepted October 27, 2020

DOI: $10.3892 / \mathrm{ol} .2020 .12351$

\begin{abstract}
The present study aimed to investigate the efficacy of a myeloid dendritic cell (mDCs) and plasmacytoid (p)DC combined vaccine loaded with heat-treated cancer cell lysates against lung cancer cells. The mDCs and pDCs were selected using magnetic bead sorting. Antigen loading was performed by adding heat-treated Lewis lung cancer cell lysates to $\mathrm{mDC}$, pDC or $\mathrm{mDC}+\mathrm{pDC}$ (1:1). Surface expression of CD80, CD86, CD40 and major histocompatibility complex (MHC)-II molecules were determined using flow cytometry, and the secretion of cytokines IL-12, IL- 6 and TNF- $\alpha$ were assessed using ELISA assays. The effect of the $\mathrm{mDC}$ and $\mathrm{pDC}$ vaccine on cytotoxic T lymphocytes (CTLs) against tumor cells was investigated. Tumor-bearing nude mice were intravenously injected with the $\mathrm{mDC}$ and $\mathrm{pDC}$ combined vaccine. Tumor tissues were collected for hematoxylin and eosin and TUNEL staining. Loading with tumor cell lysate significantly upregulated the surface expression of costimulatory molecules MHC-II on DCs and enhanced secretions of IL-6, IL-12 and TNF- $\alpha$ by DCs. In addition, the tumor cell lysate-loaded $\mathrm{mDC}$ and $\mathrm{pDC}$ combined vaccine significantly promoted lymphocyte proliferation and enhanced CTL-mediated cytotoxicity against Lewis lung cancer cells compared with mDC or pDC treatment alone. Furthermore, intravenous injection of the $\mathrm{mDC}$ and $\mathrm{pDC}$ combined vaccine into tumor-bearing
\end{abstract}

Correspondence to: Dr Lijia Gu or Dr Jian Zhang, Department of Cardiothoracic Surgery, The Third Affiliated Hospital, Sun Yat-sen University, 600 Tianhe Road, Tianhe, Guangzhou, Guangdong 510630, P.R. China

E-mail: glj58430@163.com

E-mail: zhangjian@csco.org.cn

${ }^{*}$ Contributed equally

Key words: dendritic cells vaccine, myeloid dendritic cells, plasmacytoid dendritic cells, tumor cell lysates, lung cancer nude mice significantly inhibited subcutaneous tumor growth and induced necrosis and apoptosis within the tumor tissue. Overall, the $\mathrm{pDC}$ and $\mathrm{mDC}$ combination vaccine loaded with heat-treated Lewis lung cancer cell lysate had a synergistic effect on the induction of T lymphocyte proliferation and antitumor efficacy, which may be associated with the upregulation of co-stimulatory molecules and cytokine secretions.

\section{Introduction}

Lung cancer is the leading cause of cancer-associated mortality worldwide (1). Despite advances in surgery, chemotherapy, radiotherapy and molecular targeted therapy, the prognosis of lung cancer remains poor, with a 5-year survival rate ranging from $4-17 \%$ (2). Therefore, there is a need to develop new therapeutic strategies for the treatment of lung carcinoma.

Dendritic cells (DCs) are the most potent antigenpresenting cells with a critical role in both the primary and secondary immune response against tumor-associated antigens (TAAs) (3). Vaccinations using DCs loaded with tumor lysates or specific tumor-associated peptides can trigger cytotoxic $\mathrm{T}$ cell responses against TAAs (4). However, the antitumor activity of DC vaccines remains unsatisfactory in animal models and clinical trials (5). DCs comprise of heterogeneous cell populations, the two main populations being plasmacytoid (p)DCs and myeloid (m)DCs (6). mDCs and pDCs are functionally distinct, with different toll-like receptors (TLRs; pDCs express TLR7 and TLR 9, whereas mDC express all TLRs except TLR7 and TLR9) (7) and cytokines secretion (for example, mDCs secret INF- $\lambda$, while pDCs secrete INF- $\alpha$ ) following stimulation $(8,9)$. It has been shown that mDCs and pDCs can act synergistically, resulting in improved antitumor efficacy of the vaccine. For example, a mouse model showed that a pDCs and mDCs combined vaccine has a synergistic effect and results in improved antigen-specific antitumor efficacy against thymoma compared with a pDC or mDC alone vaccine (10). However, the antitumor efficacy of a pDC and $\mathrm{mDC}$ combined vaccine against lung cancer remains to be investigated. 
Antigens loading serves an important role in the antitumor efficacy of DCs vaccines (4). Antigens used for vaccination include peptides, DNA and recombinant tumor proteins, tumor lysates, heat shock proteins, whole tumor cells and whole tumor RNAs $(11,12)$. A vaccine containing a single TAA is limited and elicits tumor-associated major histocompatibility complex (MHC) class I responses but not MHC class II and $\mathrm{CD}^{+} \mathrm{T}$ cell helper responses (13). Meanwhile, tumor lysate or whole tumor cells contain a full complement of TAAs, including both MHC class I and class II-restricted epitopes, thus decreasing the risk of immune escape $(11,12)$. Compared with a single TAA, loading with tumor lysates in DCs induces a stronger and more extensive immunological response against tumors (14-16).

The purpose of the present study was to evaluate the therapeutic efficacy of the $\mathrm{mDC}$ and $\mathrm{pDC}$ combined vaccine loaded with lung cancer cell lysates for the treatment of lung cancer.

\section{Materials and methods}

Materials and reagents. Mouse Lewis lung cancer cells were purchased from the American Type Culture collection (https://www.lgcstandards-atcc.org/products/ all/CRL-1642.aspx?geo_country=nl). Mouse anti-CD11b magnetic beads and mouse anti-mPDCA magnetic beads were purchased from Miltenyi Biotec $\mathrm{GmbH}$. Mouse IL-6 (cat. no. 555240), IL-12 (cat. no. 555256) and TNF- $\alpha$ (cat. no. 555268) ELISA kits were purchased from BD Bioscience. The TUNEL assay kit was purchased from Roche Diagnostics. Unmethylated $\mathrm{CpG}$ oligonucleotide (CpG ODN 1826) and the lactate dehydrogenase (LDH) cytotoxicity assay kit were purchased from Sangon Biotech Co., Ltd. The Cell Counting Kit (CCK)-8 was purchased from Dojindo Molecular Technologies, Inc. Recombinant Fms-like tyrosine kinase 3 receptor ligand (rmFlt3-Ligand), CD11c-PE mAb, anti-CD11b-APC mAb, anti-B220-FITC mAb, anti-MHC-II FITC mAb, anti-CD40 PE mAb, anti- CD80 PE mAb and anti-CD86 PE mAb were all purchased from eBioscience; Thermo Fisher Scientific, Inc.

Animals. In total, 35 C57BL/6 male mice (6-8 weeks old, weighing 20-25 g) and 12 NU/NU male nude mice (3-4 weeks old, weighing 9-11 g) were purchased from the Laboratory animal center of Sun Yat-sen University (http://zssom.sysu. edu.cn/cmc/). All animals were housed under standardized conditions with a 12-h light/dark cycle, humidity (50-60\%) and temperature $\left(20-27^{\circ} \mathrm{C}\right)$ with free access to food and water. All animals were monitored daily for signs of obvious behavioral changes and physical stress, and would be euthanized if found in distress. No animals were found dead or were euthanized during the experiments. All protocols used in the present study were approved by The Institutional Animal Care and Use Committee of the Third Affiliated Hospital, Sun Yat-sen University (Guangzhou, China; approval no. 00155986). The experiment was conducted between September 2016 and March 2017.

Preparation of mDCs and pDCs. After 3-5 days of breeding, the mice were sacrificed by cervical dislocation, bone marrow cells of the femur and tibia of C57BL/6 mice were collected and lysed using red blood cell lysis buffer (Sigma-Aldrich; Merck KGaA) to obtain bone marrow mononuclear cells. The cells were resuspended with RMPI-1640 complete medium (2 mM glutamine, $50 \mu \mathrm{M}$ 2-ME, $7 \mathrm{mM}$ HEPES, $100 \mathrm{U} / \mathrm{ml}$ penicillin, $100 \mu \mathrm{g} / \mathrm{ml}$ streptomycin, rmFlt3-L $100 \mathrm{ng} / \mathrm{ml}$ and $10 \%$ FBS) (Invitrogen; Thermo Fisher Scientific, Inc.) and seeded onto 6 -well plates $\left(2 \times 10^{6} / \mathrm{ml}, 1 \mathrm{ml} /\right.$ well $)$ at $37^{\circ} \mathrm{C}$ in a $5 \% \mathrm{CO}_{2}$ incubator.

On day 4 of culture, half of the medium was replaced, and fresh rmFlt3-L was added into the medium. On day 8, the $\mathrm{mDC}$ and $\mathrm{pDC}$ were sorted using mouse anti-CD11b and mouse anti-mPDCA magnetic beads according to manufacturer's protocol, and the cell purity was $>99 \%$ according to flow cytometry analysis with a FACScaliber ${ }^{\mathrm{TM}}$ cytometer (BD Biosciences) using fluorescently-labeled monoclonal antibodies (anti-CD11c-PE mAb (cat. no. 12-0401-81), anti-CD11b-APC mAb (cat. no. 17-0012-81), anti-B220-FITC $\mathrm{mAb}$ (cat. no. 11-0452-81)). The analysis software used was FlowJo version 7.6.1 (FlowJo LLC). An equal amount of pDC and $\mathrm{mDC}$ (1:1 ratio) was used for the combination vaccine (10). The sorted DC subsets were divided into three groups for subsequent experiments: mDCs, pDCs And mDCs: pDC (1:1). The number of the total cells was equal in the three groups.

DCs loaded with heat-treated with Lewis lung cancer cell lysates. Lewis lung cancer cells were cultured in high-sugar DMEM medium containing $100 \mathrm{U} / \mathrm{ml}$ penicillin, $100 \mu \mathrm{g} / \mathrm{ml}$ streptomycin and $10 \% \mathrm{FBS}$ at a concentration of $1.5-3 \times 10^{6} \mathrm{cell} / \mathrm{ml}$ in a $37^{\circ} \mathrm{C}$ and $5 \% \mathrm{CO}_{2}$ incubator. Lewis lung cancer cells in the logarithmic growth phase were placed in an incubator at $42^{\circ} \mathrm{C}$ for $1 \mathrm{~h}$, followed by placing in an incubator at $37^{\circ} \mathrm{C}, 5 \% \mathrm{CO}_{2}$ for $2 \mathrm{~h}$. The cells were digested with trypsin, washed twice with PBS and then resuspended in PBS $\left(1 \times 10^{7}\right.$ cells $\left./ \mathrm{ml}\right)$. The cells were repeatedly frozen and thawed in liquid nitrogen and $37^{\circ} \mathrm{C}$ water bath five times and centrifuged at $13,000 \times \mathrm{g}$ at $4^{\circ} \mathrm{C}$ for $10 \mathrm{~min}$. The resulting supernatant was collected as cell lysates.

Equal amounts of heat-treated tumor cell lysates were added to the mDC $\left(1 \times 10^{5}\right)$, pDC $\left(1 \times 10^{5}\right)$ and mDC: pDC (1:1; $\left.1 \times 10^{5}\right)$ groups. The amount of antigen was based on the number of tumor cells before freeze-thaw treatment with DCs: Tumor cells $=1: 1$. The control group consisted of an equal amount of RMPI-1640 complete medium, and then CpG ODN 1826 was added to each group at a final concentration of $2 \mu \mathrm{g} / \mathrm{ml}$. The cell was cultured for $24 \mathrm{~h}$ to induce DC maturation for subsequent experiments.

Mixed lymphocyte proliferation assay. C57BL/6 mouse spleens were taken and cut with ophthalmology scissors, placed on a $70-\mu \mathrm{m}$ filter screen, and ground with a 1-ml syringe plunger and rinsed with PBS while grinding. The spleen cells suspension was collected in a centrifuge tube and centrifuged at $300 \mathrm{x} \mathrm{g}$ for $5 \mathrm{~min}$, and the supernatant was discarded. The red blood cell lysis buffer was added and incubated for $1 \mathrm{~min}$, and the RPMI-1640 medium was immediately added to stop the reaction, then centrifuged at $300 \mathrm{x}$ g for $5 \mathrm{~min}$. After washing twice with PBS, the resulting pellet was collected as spleen cells. These experiments were performed at room temperature $\sim 25^{\circ} \mathrm{C}$. 
DCs loaded with heat-treated tumor cell lysates from the three groups of $\mathrm{mDC}, \mathrm{pDC}$ and $\mathrm{mDC}+\mathrm{pDC}$ were added to 96-well culture plates at $1 \times 10^{4}$ cells/well. C57BL/6-derived spleen cells were added into each well $\left(1 \times 10^{5}\right.$ cells $/$ well; DCs: Spleen cells =1:10) and cultured for 3 days. The DCs of each group without tumor cell lysate loading were used as control groups. There were three duplicated wells in each group. The proliferation of spleen cells was detected using the CCK-8 assay according to the manufacturer's protocol.

CTL cytotoxicity assay. DC cells in three groups loaded with heat-treated tumor cell lysate were co-cultured in vitro by DCs: Spleen cells =1:10. There were three duplicated wells in each group. Recombinant mouse IL-2 was added into each well at a final concentration of $20 \mathrm{U} / \mathrm{ml}$, and the solution was replaced every 3 days and cultured at $37^{\circ} \mathrm{C}, 5 \% \mathrm{CO}_{2}$. After culture for a week, the cells were trypsinized and collected as the CTL cells.

Lewis lung cancer cells in the logarithmic growth phase were used as target cells, and CTL cells were used as effector cells. The effector and target cells were mixed at the effector: Target cell ratios (E:T) of 40:1 (CTL:tumor cells, $4 \times 10^{5}: 1 \times 10^{4}$ ), 20:1 (CTL:tumor cells, $2 \times 10^{5}: 1 \times 10^{4}$ ) and 10:1 (CTL:tumor cells, $1 \times 10^{5}: 1 \times 10^{4}$ ) in $100 \mu \mathrm{l}$ medium, and plated onto a 96-well flat-bottom plate and co-cultured for $12 \mathrm{~h}$. There were three duplicated wells in each group. At $1 \mathrm{~h}$ before the end of co-culture, $10 \mu \mathrm{l}$ of $\mathrm{LDH}$ releasing agent (Beyotime Institute of Biotechnology) was added into each well and incubated at $37^{\circ} \mathrm{C}, 5 \% \mathrm{CO}_{2}$ for $1 \mathrm{~h}$. At the end of the culture, the absorbance at $490 \mathrm{~nm}$ (OD value) was measured using a microplate reader.

Determining surface markers on DCs and cytokines secretion. For surface marker labeling, the cell suspension was incubated with anti-CD11c-PE $\mathrm{mAb}$ (cat. no. 12-0401-81), anti-CD11b-APC mAb (cat. no. 17-0012-81), anti-B220-FITC mAb (cat. no. 11-0452-81), anti-mouse CD80 PE-Cy7 (cat. no. 15-0801-81), anti-mouse CD86 APC (cat. no. 17-0862-81), anti-mouse CD40 PE (cat. no. 12-0401-81) and anti-mouse MHC Class II FITC (cat. no. 11-5322-81) fluorescent antibodies at $20^{\circ} \mathrm{C}$ for $20 \mathrm{~min}$ in the dark. All the antibodies were diluted by 1:100. The cells were washed twice with PBS, resuspended in $300 \mu \mathrm{l}$ PBS containing 1\% FBS (Invitrogen; Thermo Fisher Scientific, Inc.), and subjected to flow cytometry as aforementioned. The experiment was repeated three times. The analysis software used was Flowjo version 7.6.1 (FlowJo, LLC). CD11c positive cells were gated, CD11b-B220+ was identified as pDC subpopulation and $\mathrm{CD} 11 \mathrm{~b}+\mathrm{B} 220$ - was defined as mDC subpopulation. The secretion level of IL-6, IL-12 and TNF- $\alpha$ in the aforementioned cell supernatant was detected using the corresponding ELISA kit according to the manufacturer's protocols.

Establishment of tumor-bearing nude mice model. Lewis lung cancer cells in the logarithmic growth phase were resuspended at a cell density of $1 \times 10^{7} / \mathrm{ml}$. The cell suspension $(0.1 \mathrm{ml}$; $1 \times 10^{6}$ cells) was injected subcutaneously into the thigh roots of $12 \mathrm{NU} / \mathrm{NU}$ male nude mice to establish tumor-bearing nude mice. The tumor-bearing mice were randomly divided into three groups: Control, $\mathrm{mDC}$ group and the $\mathrm{mDC}+\mathrm{pDC}$ group, with four mice per group.

Preparation of CTLs. The tumor cell lysate-sensitized mDCs and pDCs were added to the 6-well plate culture well $\left(1 \times 10^{6} / \mathrm{ml}\right.$ per well). The ratio of DCs: Antigen was $1: 1$, and the amount of antigen was based on the number of tumor cells before freeze-thaw treatment. DC maturation was induced by the addition of CpG ODN1826 at a final concentration of $2 \mu \mathrm{g} / \mathrm{ml}$ overnight. The cells in the wells were collected, and the cell suspension was prepared at the cell density of $3 \times 10^{6} / \mathrm{ml}$. Mouse spleen cells were collected as aforementioned.

The DCs and spleen cells were mixed at a ratio of 1:10 and then added to a 6 -well plate $\left(3 \times 10^{6}\right.$ cells $/ \mathrm{ml}, 2 \mathrm{ml}$ per well with $6 \times 10^{6}$ cells/well). rmIL-2 was added at a final concentration of $20 \mathrm{U} / \mathrm{ml}$ The culture medium was replaced with complete RMPI-1640 medium containing IL-2 once every 3 days and then incubated for 2 weeks in a $37^{\circ} \mathrm{C}$ in a $5 \% \mathrm{CO}_{2}$ incubator. The resulting cells were CTLs.

In vivo antitumor study of DC vaccine. Tumor-bearing mice were randomly divided into three groups: Control, $\mathrm{mDC}$ group and the $\mathrm{mDC}+\mathrm{pDC}$ group. At day 7 post the inoculation of Lewis lung cancer cells, PBS, mDC-induced CTL cells and $\mathrm{mDC}+\mathrm{pDC}$ induced CTL cells $\left(1 \times 10^{7}\right.$ cells/mouse) were intravenously injected into mice in the three groups through the tail vein. The injection of CTL cells was repeated 7 days after the first injection.

The length (L) and width (D) of the tumor tissue were measured with a vernier caliper, and the tumor volume was calculated every 2 days. The tumor volume was calculated according to the formula $\mathrm{V}=1 / 2 \mathrm{LxD}^{2}$.

At 25 days after the inoculation of Lewis lung cancer cells, nude mice were sacrificed by cervical dislocation, and then tumor tissues were collected. The necrosis of tumor tissues was observed by hematoxylin and eosin (H\&E) staining. For $\mathrm{H} \& \mathrm{E}$ staining, tissue samples were fixed with $10 \%$ formalin for $24 \mathrm{~h}$, then embedded in paraffin and sectioned into slices with a thickness of $5 \mu \mathrm{m}$. After dewaxing with xylene and rehydration with descending ethanol series [100 (twice), 90, 80 and $70 \%$ respectively], the slice was stained with $\mathrm{H}$ for $5 \mathrm{~min}, 5 \%$ acetic acid for $1 \mathrm{~min}$, and eosin staining for $1 \mathrm{~min}$ at room temperature $25^{\circ} \mathrm{C}$. After dehydration with ascending ethanol series $(70,80,90$ and $100 \%$ respectively), the slide was dripped with neutral resin, covered with a cover glass, and then mounted. TUNEL staining was used to observe the apoptosis of tumor cells by using the aforementioned TUNEL assay kit according to the manufacturer's protocol. The apoptotic cells were observed under a fluorescence microscope (excitation light wavelength, 450-500 $\mathrm{nm}$; detection wavelength, 515-565 nm).

Statistical analysis. All data was presented as mean \pm SD and were compared using one-way ANOVA (for one independent variable) or two-way ANOVA (for two independent variables) with Sidak's post hoc test for multiple comparisons. $\mathrm{P}<0.05$ was considered to indicate a statistically significant difference. Statistical analyses were performed using SPSS version 16 software (SPSS Inc.). 


\section{Results}

Combining tumor cell lysate-loaded $m D C$ and $p D C$ promotes lymphocyte proliferation. The effect of $\mathrm{mDC}$ and $\mathrm{pDC}$ vaccines on lymphocyte proliferation was determined using a CCK-8 assay. As shown in Fig. 1, in both the absence or presence of tumor cell lysates, the lymphocyte proliferation was significantly higher in the $\mathrm{mDC}+\mathrm{pDC}$ group compared with the $\mathrm{mDC}$ or $\mathrm{pDC}$ group (all $\mathrm{P}<0.05$ ). After loading with tumor cell lysate, the promotive effect on lymphocytes proliferation was significantly increased in the three groups (all $\mathrm{P}<0.001$ without tumor lysate vs. with tumor lysate; Fig. 1).

Combining tumor cell lysate-loaded $m D C$ and $p D C$ enhances CTL-mediated cytotoxicity against tumor cells. The effect of $\mathrm{mDC}$ and $\mathrm{pDC}$ vaccines on CTL cytotoxicity against tumor cells was investigated. In the absence of tumor cell lysates, there was no difference in CTL cytotoxicity among the three groups at all the effector: Target cell ratios (E:T), (all P>0.05; Fig. 2).

Tumor cell lysate loading significantly enhanced the CTL-mediated cytotoxicity in all the groups at all the E:T (all $\mathrm{P}<0.001$ without tumor lysate vs. with tumor lysate; Fig. 2). At all the three E:T, the mDC+pDC group had significantly higher cytotoxicity compared with the $\mathrm{mDC}$ or $\mathrm{pDC}$ group (all $\mathrm{P}<0.05$; Fig. 2). The cytotoxicity of the $\mathrm{mDC}+\mathrm{pDC}$ group was $31.68,54.77$ and $73.01 \%$ at the E:T of 1:10, 1:20 and 1:40 (Fig. 2), respectively.

Heat-treated tumor cell lysate loading upregulates the DCs surface expression of costimulatory molecules. Surface expressions of costimulatory molecules, including CD80, CD86, CD40 and MHC-II, were assessed using flow cytometry (Fig. 3A). The results showed that in the absence of tumor cell lysate, the surface expressions of MHC-II were significantly higher in the $\mathrm{mDC}+\mathrm{pDC} / \mathrm{TCL}^{-}$group compared with the $\mathrm{mDC}^{\mathrm{TCCL}} \mathrm{L}^{-}$or $\mathrm{pDC} / \mathrm{TCL}^{-}$group (all $\mathrm{P}<0.05$; Fig. $3 \mathrm{~B}$ ). After loading with the tumor cell lysate, the surface expressions of CD86 and MHC-II were significantly higher in the $\mathrm{mDC}+\mathrm{pDC} / \mathrm{TCL}^{+}$group compared with those in the $\mathrm{mDC} / \mathrm{TCL}^{+}$or $\mathrm{pDC}$ group $/ \mathrm{TCL}^{+}($all $\mathrm{P}<0.05$; Fig. $3 \mathrm{~B})$. In addition, after loading with the tumor cell lysate, surface expression of MHC-II was significantly increased in all cell types (all $\mathrm{P}<0.05$; Fig. 3B).

Tumor cell lysate loading stimulates cytokines secretion in DCs. The secretion of cytokines in DCs was determined using ELISA kits. As shown in Fig. 4, tumor cell lysate loading significantly upregulated the secretions of IL-6, IL-12 and TNF- $\alpha$ in the $\mathrm{mDC}+\mathrm{pDC}=1: 1$ group (all $\mathrm{P}<0.001$ ). In addition, in both the absence or presence of tumor cell lysates, secretions of IL-6, IL-12 and TNF- $\alpha$ were significantly higher in the $\mathrm{mDC}+\mathrm{pDC}$ group compared with those in the $\mathrm{mDC}$ or pDC group $(\mathrm{P}<0.05$; Fig. 4), except for mDC:pDC without tumor lysate vs. mDC without tumor lysate for IL-6.

$m D C$ and $p D C$ combined vaccine inhibits tumor growth in nude mice. The in vitro results indicated that DCs vaccines loaded with tumor cell lysates induced a strong antitumor effect, and the mDC and pDC combined vaccine loaded with

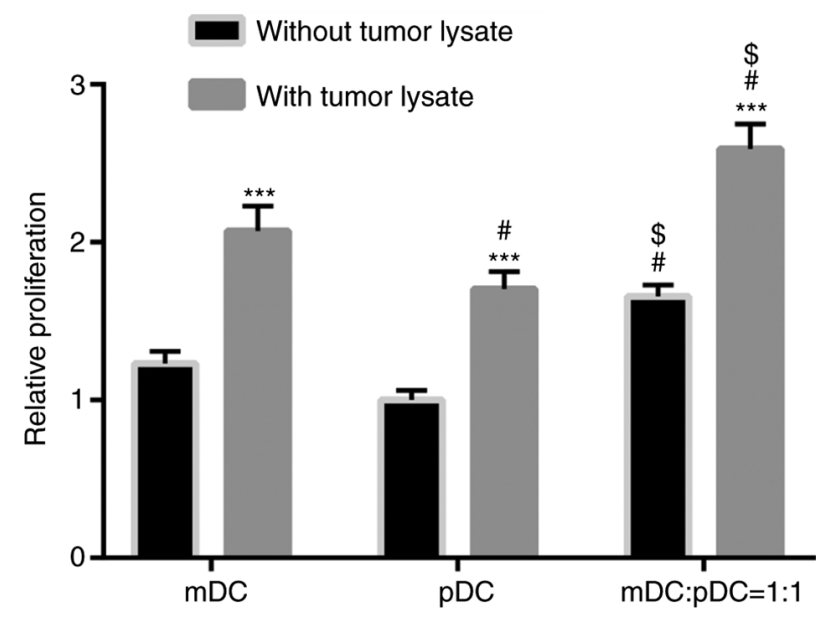

Figure 1. Stimulation of lymphocyte proliferation by DCs among the groups. Data were analyzed using a two-way ANOVA with Sidak's post hoc test. ${ }^{* * * *} \mathrm{P}<0.001$ vs. the same cell type without tumor lysate treatment. ${ }^{*} \mathrm{P}<0.05$ vs. mDC group. ${ }^{\$} \mathrm{P}<0.05$ vs. $\mathrm{pDC}$ group with the same treatment. $\mathrm{m}$, myeloid; $\mathrm{p}$, plasmacytoid; DCs, dendritic cells.

tumor cell lysates exhibited a synergistic antitumor effect in vitro. To further evaluate the antitumor effect of the $\mathrm{mDC}$ and $\mathrm{pDC}$ combined vaccine in vivo, a tumor-bearing nude mice model was established. The pDC alone group was not included in the animal study because this group exhibited the lowest in vitro antitumor effect. After 7 days post subcutaneous inoculation of Lewis lung cancer cells in nude mice, all mice developed a subcutaneous mass and were administrated with the first DC vaccine. At 14 days after inoculation, a second $\mathrm{DC}$ vaccine was administrated. It was observed that between 11 and 25 days after inoculation, the tumor volume was significantly lower in the $\mathrm{mDC}+\mathrm{pDC}$ group compared with the control group (all $\mathrm{P}<0.05$ or $\mathrm{P}<0.01$; Fig. $5 \mathrm{~B}$ ). In addition, the tumor volume was all significantly lower in the $\mathrm{mDC}+\mathrm{pDC}$ group compared with the $\mathrm{mDC}$ group (Fig. 5B). This result suggested that the $\mathrm{mDC}$ and $\mathrm{pDC}$ combined vaccine had a good in vivo antitumor effect.

Histological changes of tumor cells after $m D C$ and $p D C$ combined vaccine treatment. Histological changes in tumor cells following DC vaccine treatment were evaluated. H\&E staining showed that in the control group, the tumor cells had different sizes and obvious atypia (Fig. 6A, black arrow). The cancer cells were round, elliptical or fusiform in shape. There was no tumor giant cell or necrosis. Tumor cells in the $\mathrm{mDC}$ group showed focal necrosis and hemorrhage (Fig. 6B, blue arrow), while those in the $\mathrm{mDC}+\mathrm{pDC}$ group exhibited massive necrosis and hemorrhage (Fig. 6C, white arrow).

$m D C$ and $p D C$ combined vaccine treatment induces apoptosis in tumor cells. A TUNEL assay was performed to assess the number of apoptotic tumor cells after DC vaccine treatment (Fig. 7A-C). The results showed that the number of apoptotic tumor cells was significantly higher in the $\mathrm{mDC}+\mathrm{pDC}=1: 1$ group compared with the mDC group and the control group (both $\mathrm{P}<0.01$; Fig. 7D), indicating that the $\mathrm{mDC}$ and $\mathrm{pDC}$ combined vaccine treatment decreased apoptosis within the tumor. 


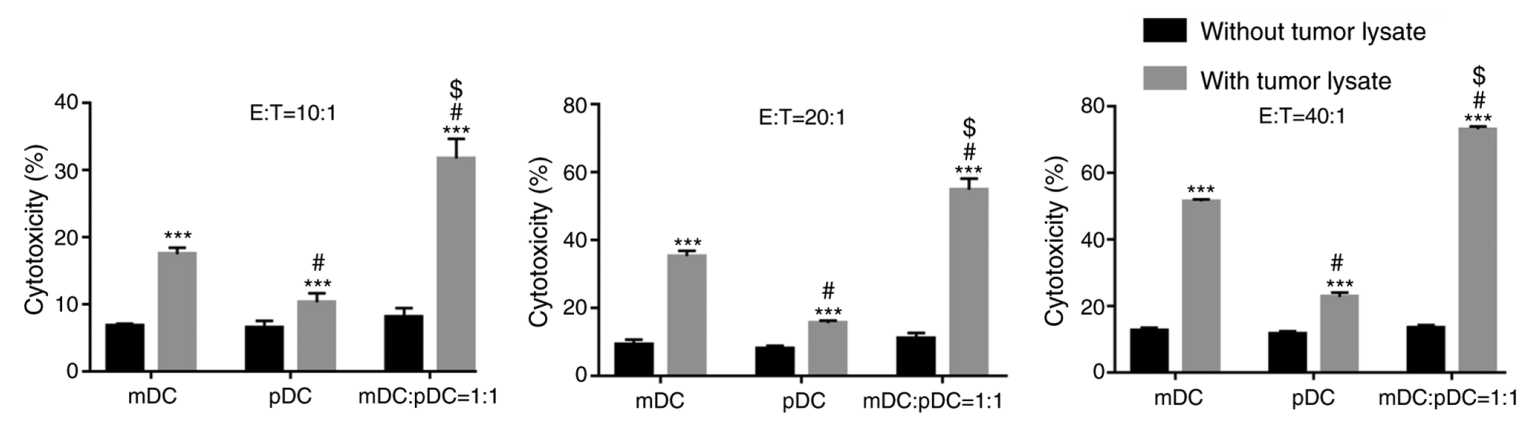

Figure 2. DCs cells induce cytotoxic T lymphocytes cytotoxicity against lung cancer cells. Two-way ANOVA with Sidak's post hoc test. ${ }^{* * *} \mathrm{P}<0.001 \mathrm{vs}$. the same cell type without tumor lysate treatment. ${ }^{\sharp} \mathrm{P}<0.05$ vs. mDC group. ${ }^{\circledR} \mathrm{P}<0.05$ vs. pDC group with the same treatment. m, myeloid; p, plasmacytoid; DCs, dendritic cells.
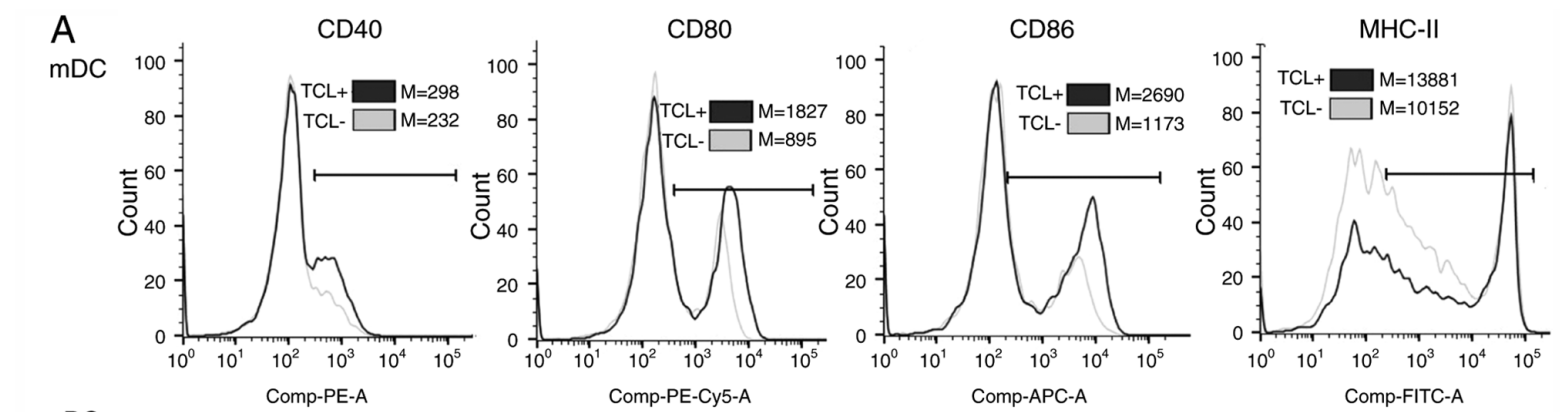

pDC
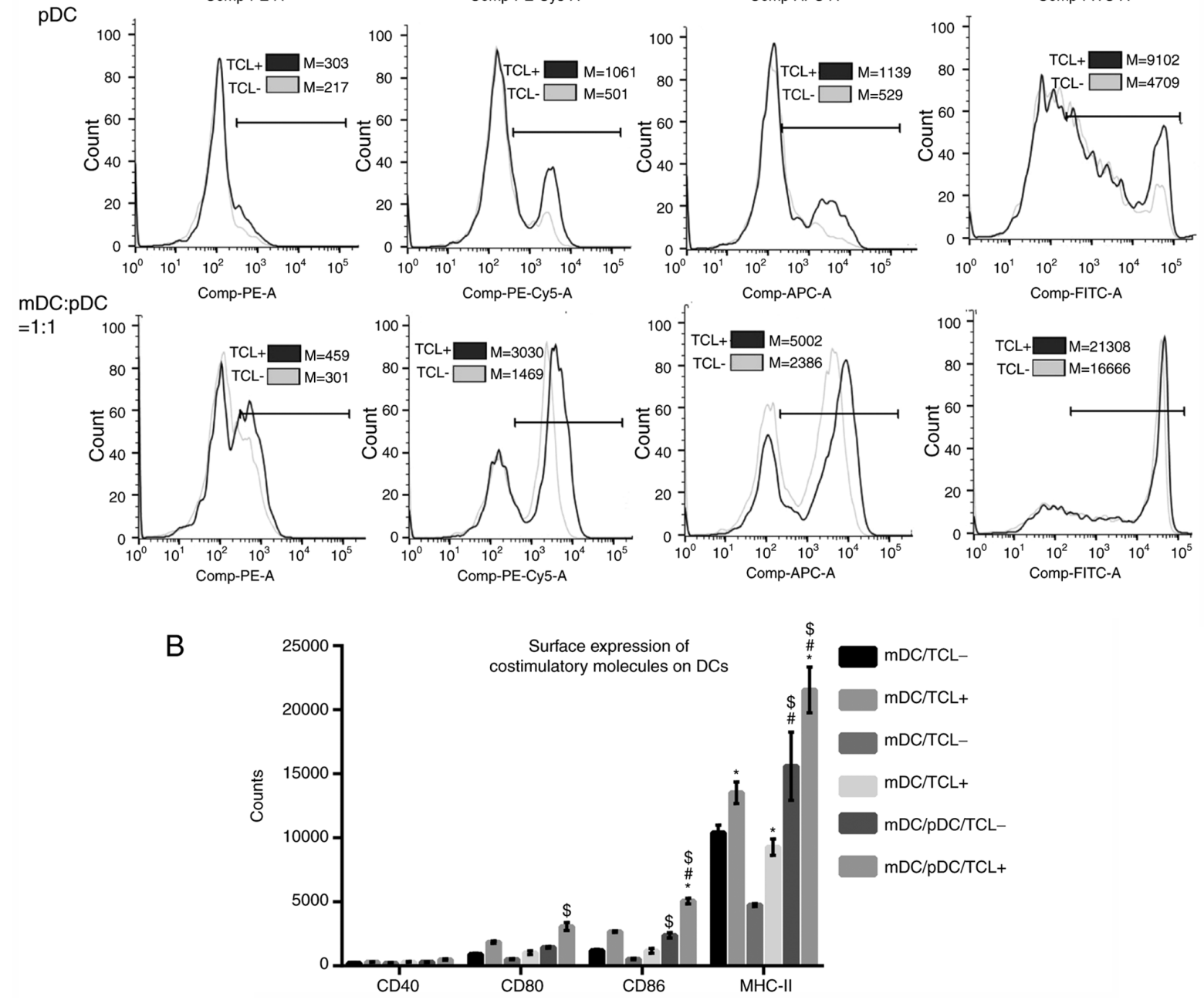

Figure 3. Surface expression of costimulatory molecules. (A) Flow cytometry results and (B) quantification. Data were analyzed using a two-way ANOVA with Sidak's post hoc test. ${ }^{~} \mathrm{P}<0.05$ vs. the same cell type without tumor lysate treatment. ${ }^{*} \mathrm{P}<0.05$ vs. $\mathrm{mDC}$ group. ${ }^{\mathrm{S}} \mathrm{P}<0.05$ vs. pDC group with the same treatment (with or without tumor lysate). m, myeloid; p, plasmacytoid; DCs, dendritic cells; TCL-, without heat-treated tumor cell lysate; TCL+, loaded with heat-treated tumor cell lysate. 


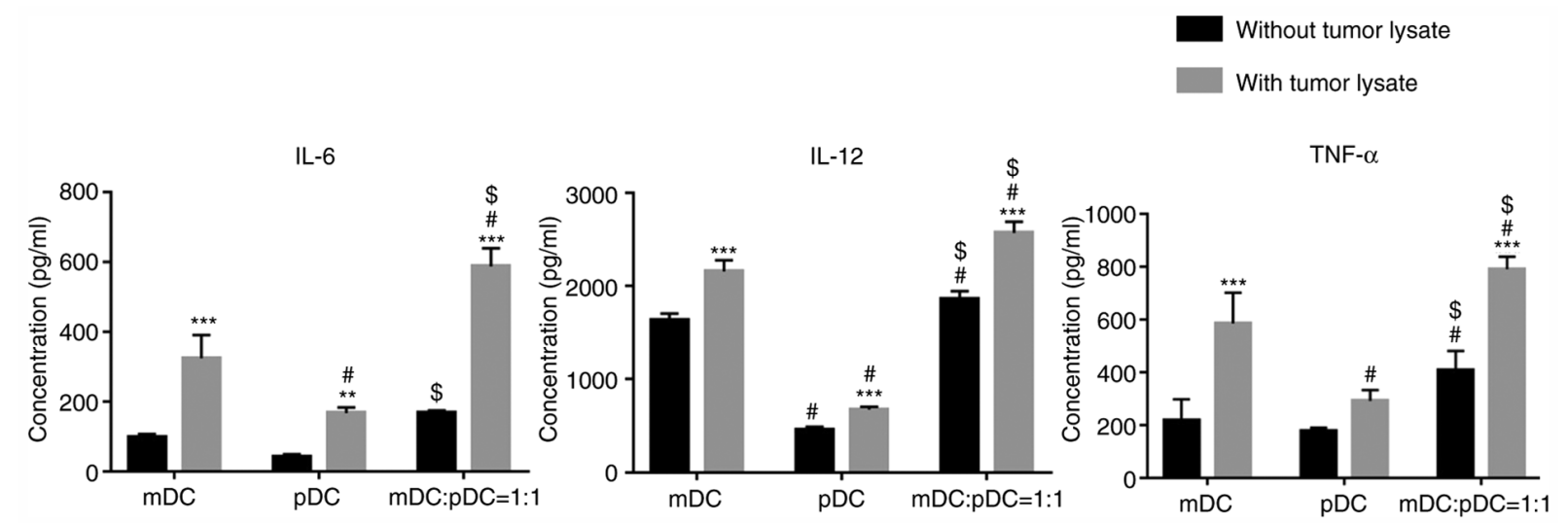

Figure 4. Cytokine secretion of DCs in each group. Two-way ANOVA with Sidak's post hoc test. ${ }^{* *} \mathrm{P}<0.01$ and ${ }^{* * *} \mathrm{P}<0.001$ vs. the same cell type without tumor lysate treatment. ${ }^{\#} \mathrm{P}<0.05$ vs. mDC group. ${ }^{~} \mathrm{P}<0.05$ vs. pDC group with the same treatment (with or without tumor lysate). m, myeloid; $\mathrm{p}$, plasmacytoid; DCs, dendritic cells.
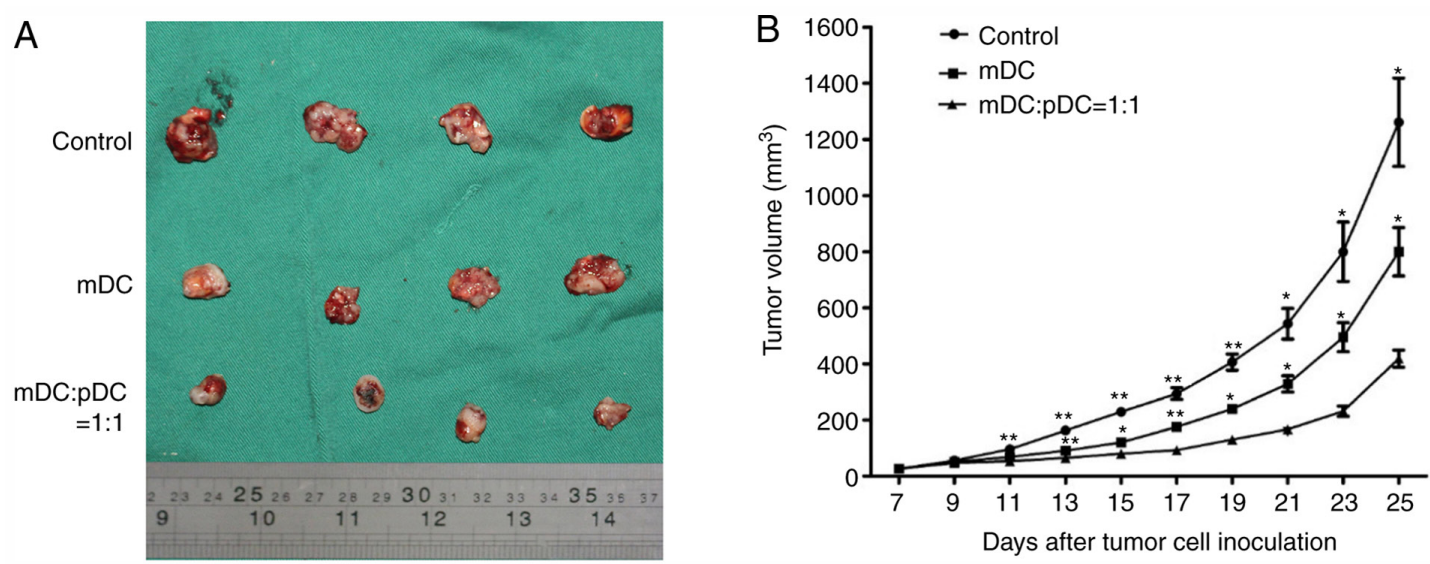

Figure 5. Tumor-bearing nude mice model was established by subcutaneous injection of Lewis lung cancer cells, and thee mDC and pDC combined vaccine were intravenously injected. Tumor volume was measured every 2 days. (A) At 25 days after cancer cell inoculation, nude mice were sacrificed and tumor tissues were collected. (B) Growth curve of tumor volume from day 7 to day 25 . One-way ANOVA with Sidak's post-hoc test. " $\mathrm{P}<0.05$ and ${ }^{* *} \mathrm{P}<0.01$ vs. the mDC:pDC=1:1 group. m, myeloid; p, plasmacytoid; DCs, dendritic cells.

\section{Discussion}

The use of the DC vaccine for tumor immunotherapy has not yet achieved satisfactory results (5). Therefore, how to enhance the antigen presentation ability of the DC vaccine in vivo and how improve the clinical efficacy of the vaccine have been focuses of research. The present study evaluated the therapeutic efficacy of the $\mathrm{mDC}$ and $\mathrm{pDC}$ combined vaccine loaded with heat-treated cancer cell lysates for the treatment of lung cancer and the underlying mechanism. The results showed that tumor cell lysate loading upregulated surface expression of costimulatory molecules on DCs and enhanced secretions of IL-6, IL-12 and TNF- $\alpha$ in the $\mathrm{mDC}+\mathrm{pDC}=1: 1$ group. In addition, combining tumor cell lysate-loaded $\mathrm{mDCs}$ and $\mathrm{pDCs}$ significantly promoted lymphocyte proliferation and enhanced CTL-mediated cytotoxicity against Lewis lung cancer cells compared with $\mathrm{mDC}$ or $\mathrm{pDC}$ alone treatment. Furthermore, intravenous injection of the $\mathrm{mDC}$ and $\mathrm{pDC}$ combined vaccine into tumor-bearing nude mice significantly inhibited subcutaneous tumor growth and induced necrosis and apoptosis within the tumor tissue. Taken together, these results suggested that the combined $\mathrm{pDC}$ and $\mathrm{mDC}$ vaccine loaded with heat-treated
Lewis lung cancer cell lysate had a synergistic effect on the induction of $\mathrm{T}$ lymphocyte proliferation and antitumor efficacy. This synergistic antitumor effect may be associated with the upregulation of co-stimulatory molecules and cytokine secretions.

The method for preparing tumor lysates affects the efficacy of the DCs vaccine. It has been shown that freeze-thaw tumor cell lysates do not effectively mimic in vivo immunogenic necrosis and inhibit the maturation and function of DCs (17-20). Hatfield et al (20) reported that heat-treated tumor lysates $\left(\geq 42^{\circ} \mathrm{C}\right)$ compared with tumor lysates are more effective TAAs for DC vaccination. DCs loaded with heat-treated tumor cell lysates can induce strong and broad $\mathrm{T}$ cell responses against pancreatic cancer, thereby enhancing antitumor effects (21). Heat treatment increases the synthesis of heat shock protein (HSP) in tumor cells, and HSP may promote the expression of TAAs and enhance their presentation to antigen-presenting cells (22). Stress-induced HSP can also induce the expression of MHC-II molecules, and cytokine and chemokine secretions in DCs (23). Therefore, the present study adopted heat treatment to prepare tumor cells lysates for DC vaccination. 
A

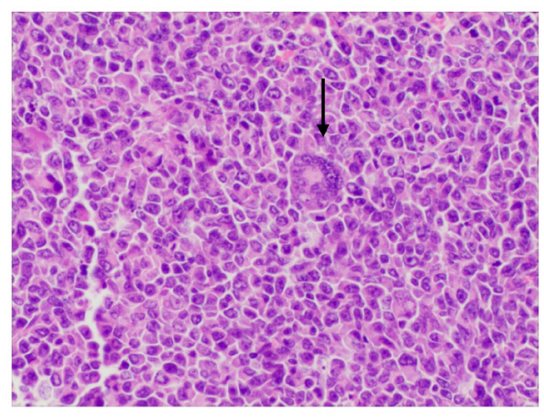

B

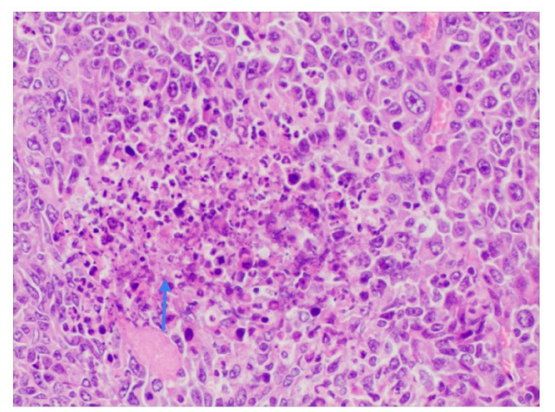

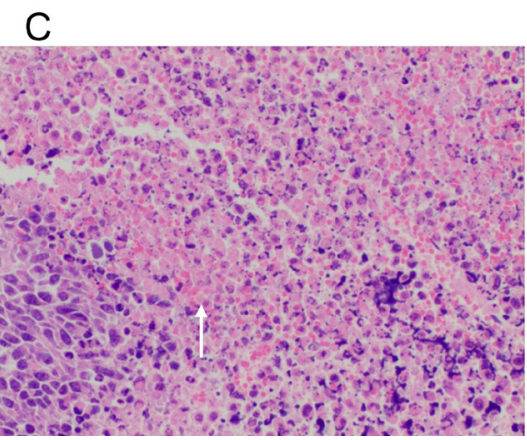

Figure 6. Hematoxylin and eosin staining of tumor tissue of (A) the control, (B) mDC and (C) mDC+ plasmacytoid DC groups. Black arrow indicates the tumor cells with obvious atypia. Blue arrow indicates focal necrosis and hemorrhage, while arrow indicates massive necrosis and hemorrhage. Magnification, x200. m, myeloid; DCs, dendritic cells.
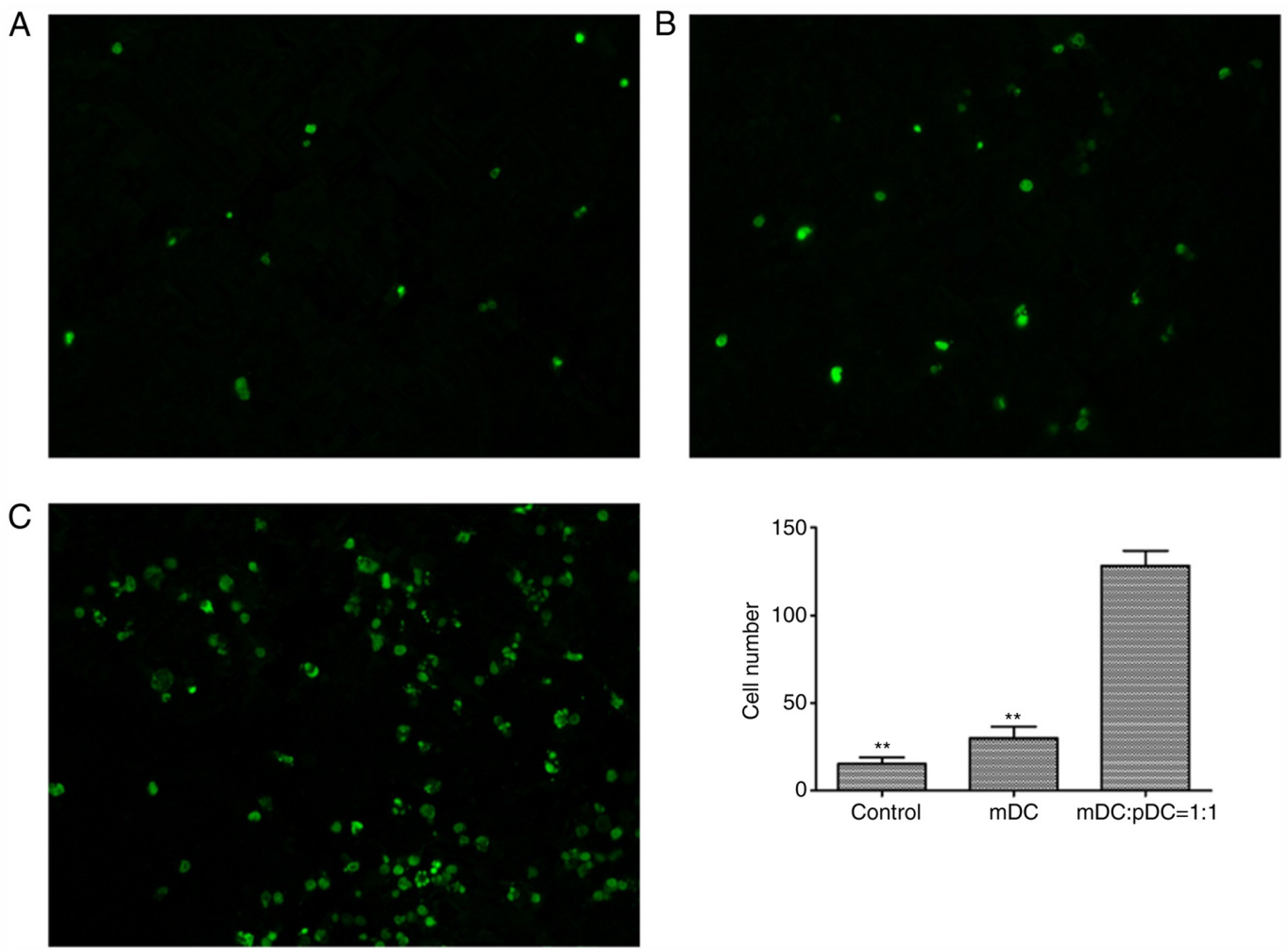

Figure 7. TUNEL staining of tumor tissue of the (A) control (A), (B) mDC (B) and (C) mDC+pDC groups. Magnification, x200. Three fields were observed for each group. (D) The number of tumor cell apoptosis in the $\mathrm{mDC}$ : $\mathrm{pDC}=1: 1$ group was significantly higher than that in the mDC and Control groups. One-way ANOVA with Sidak's post hoc test. ${ }^{* *} \mathrm{P}<0.01$ vs. the mDC+pDC group. m, myeloid; p, plasmacytoid; DCs, dendritic cells.

The present study used nude mice to generate a tumor model. In our preliminary study, C57BL rats were used to generate a tumor model, but the rate of tumor formation was low, with a small tumor volume and relatively long tumor 
formation time (unpublished data). In addition, DC-activated lymphocytes, rather than the DC vaccine, were transplanted into the animals. The C57BL rats inoculated with subcutaneous tumor would produce specific $\mathrm{T}$ cells against tumor that can affect the antitumor activity of the injected DC-activated lymphocytes. Since nude mice lack lymphocytes, this problem can be overcome. In the present study, the experimental animals were the NU/NU nude mice that lack thymus and $\mathrm{T}$ lymphocytes (24). The activation of $\mathrm{T}$ lymphocytes requires antigen and accessory molecules to effectively induce CTL formation (25). Therefore, the DC vaccines could not be directly injected into tumor-bearing nude mice. T lymphocytes should be activated in vitro and then the CTL effector cells infused into the animal. Previous studies have shown that antigen-loaded DCs induce T lymphocytes in vitro, and infusion of CTL effector cells exhibits significant antitumor effects in mice (26-28), which are in line with the present results.

Lou et al (10) demonstrated that pDCs and mDCs have a synergistic effect on the induction of antigen-specific antitumor immune responses. Piccioli et al reported that human $\mathrm{mDC}$ and pDC mixed culture can upregulate the expression of DC activation markers CD40, CD80 and CD83, which can enhance the proliferation of allogeneic T cells and secrete more IFN- $\gamma$ compared with single pDC or mDC alone (29). Consistent with these observations, the present results demonstrated that compared with $\mathrm{mDC}$ or $\mathrm{pDC}$ alone treatment, combining tumor lysate-loaded $\mathrm{mDC}$ and $\mathrm{pDC}$ enhanced lymphocyte proliferation and CTL-mediated cytotoxicity in vitro. The in vivo experiments showed that the $\mathrm{MDC}$ and $\mathrm{pDC}$ combined vaccine inhibited subcutaneous tumor growth, and induced extensive necrosis, hemorrhage and apoptosis within the tumor tissue. The efficacy of the combined vaccines was improved compared with that of the mDC group. These results suggested that the mDC and $\mathrm{pDC}$ combined vaccine exhibited a synergistic antitumor effect against lung cancer cells. To the best of our knowledge, the present study is the first to demonstrate the efficacy of mDC and $\mathrm{pDC}$ vaccine combined against lung cancer.

Our results demonstrated that the combined mDCs and pDCs induced increased secretion of IL-12, IL-6 and TNF- $\alpha$ compared with $\mathrm{mDC}$ or $\mathrm{pDC}$ treatment alone, and upregulated surface costimulatory molecules and MHC-II expression. Immature DCs undergo a complex maturation process after antigen capture, during which DCs upregulate cell surface costimulatory molecules, such as CD80, CD86 and CD40, that enhances the ability of DCs to activate T cells (30). IL-12 is the most important cytokine secreted by DCs, regulating the balance between the Thelper (h) 1 and Th2 response, and further promoting the maturation of DC (31). IL- 6 can promote T and $\mathrm{B}$ cell proliferation and differentiation, antibody production, DC maturation and enhance DC antigen presentation (32). TNF- $\alpha$ can promote DC maturation and increase the viability of DCs in an autocrine or paracrine manner, and indirectly promote DC antigen presentation (32). Therefore, the synergistic effect of the $\mathrm{mDC}$ and $\mathrm{pDC}$ combined vaccine observed in the present study may be associated with upregulated surface costimulatory molecules expression and cytokine secretions. However, the detailed molecular mechanisms underpinning this need to be further elucidated.

There are still some limitations to the present study. First, the number of mDCs and pDCs after magnetic bead sorting was limited, which were insufficient for large-scale animal experiments. In addition, although an equal amount of $\mathrm{mDC}$ and $\mathrm{pDC}$ exhibited a synergistic antitumor effect, the optimized ratio of $\mathrm{mDC}$ and $\mathrm{pDC}$ remains to be investigated. Moreover, to minimize the number of animals used, the $\mathrm{pDC}$ alone group was not included in the animal study because this group exhibited the lowest in vitro antitumor effect. All these limitations should be addressed in the future study.

In summary, the present study suggested that the mixed culture of $\mathrm{mDC}$ and $\mathrm{pDC}$ produced a synergistic effect, which enhanced the cytotoxic effect of T lymphocytes against Lewis lung cancer cells in vitro and in vivo. These results may help improve the design and clinical efficacy of DC vaccines.

\section{Acknowledgements}

Not applicable.

\section{Funding}

The study was supported by The Science and Technology Planning Project of Guangdong Province (grant no. 20130319c).

\section{Availability of data and materials}

All data generated or analyzed during this study are included in this published article.

\section{Authors' contributions}

LG and JZ designed the study. HC and JT conducted the experiments, collected and analyzed the data and drafted the manuscript. XL guided and performed the experiments and revised the manuscript. HL, WW and YW cultured the cells and determined the level of cytokines. All authors read and approved the final version of the manuscript.

\section{Ethics approval and consent to participate}

All protocols used in the present study were approved by The Institutional Animal Care and Use Committee of the Third Affiliated Hospital (Guangzhou, China; approval no. 00155986).

\section{Patient consent for publication}

Not applicable.

\section{Competing interests}

The authors declare that they have no competing interests.

\section{References}

1. Mellstedt H, Vansteenkiste J and Thatcher N: Vaccines for the treatment of non-small cell lung cancer: Investigational approaches and clinical experience. Lung Cancer 73: 11-17, 2011.

2. Hirsch FR, Scagliotti GV, Mulshine JL, Kwon R, Curran WJ, Wu YL and Paz-Ares L: Lung cancer: Current therapies and new targeted treatments. Lancet 389: 299-311, 2017.

3. Gardner A and Ruffell B: Dendritic cells and cancer immunity. Trends Immunol 37: 855-865, 2016. 
4. González FE, Gleisner A, Falcón-Beas F, Osorio F, López MN and Salazar-Onfray F: Tumor cell lysates as immunogenic sources for cancer vaccine design. Hum Vaccines Immunother 10: 3261-3269, 2014

5. Ilett E, Prestwich R and Melcher A: The evolving role of dendritic cells in cancer therapy. Expert Opin Biol Ther 10: 369-379, 2010.

6. Bol KF, Schreibelt G, Gerritsen WR, De Vries IJM and Figdor CG: Dendritic cell-based immunotherapy: State of the art and beyond. Clin Cancer Res 22: 1897-1906, 2016.

7. Kadowaki N, Ho S, Antonenko S, Malefyt R, Kastelein R, Bazan F and Liu Y: Subsets of human dendritic cell precursors express different toll-like receptors and respond to different microbial antigens. J Exp Med 194: 863-869, 2001.

8. Swiecki M and Colonna M: The multifaceted biology of plasmacytoid dendritic cells. Nat Rev Immunol 15: 471-485, 2015.

9. Nizzoli G, Krietsch J, Weick A, Steinfelder S, Facciotti F, Gruarin P, Bianco A, Steckel B, Moro M, Crosti M, et al: Human $\mathrm{CD} 1 \mathrm{c}^{+}$dendritic cells secrete high levels of IL-12 and potently prime cytotoxic T-cell responses. Blood 122: 932-942, 2013.

10. Lou Y, Liu C, Kim GJ, Liu YJ, Hwu P and Wang G: Plasmacytoid dendritic cells synergize with myeloid dendritic cells in the induction of antigen-specific antitumor immune responses. J Immunol 178: 1534-1541, 2007.

11. Mocellin S, Mandruzzato S, Bronte V, Lise M and Nitti D: Part I Vaccines for solid tumours. Lancet Oncol 5: 681-689, 2004.

12. Schuler G, Schuler-Thurner B and Steinman RM: The use of dendritic cells in cancer immunotherapy. Curr Opin Immunol 15 138-147, 2003

13. Tagliamonte M, Petrizzo A, Tornesello ML, Buonaguro FM and Buonaguro L: Antigen-specific vaccines for cancer treatment. Hum Vaccines Immunother 10: 3332-3346, 2014.

14. Ridolfi R, Petrini M, Fiammenghi L, Stefanelli M, Ridolfi L, Ballardini M, Migliori G and Riccobon A: Improved overall survival in dendritic cell vaccination-induced immunoreactive subgroup of advanced melanoma patients. J Transl Med 4: 36, 2006.

15. Trefzer U, Herberth G, Wohlan K, Milling A, Thiemann M, Sharav T, Sparbier K, Sterry W and Walden P: Tumour-dendritic hybrid cell vaccination for the treatment of patients with malignant melanoma: Immunological effects and clinical results. Vaccine 23: 2367-2373, 2005.

16. Nagayama H, Sato K, Morishita M, Uchimaru K, Oyaizu N, Inazawa $T$, Yamasaki $T$, Enomoto $M$, Nakaoka $T$, Nakamura T, et al: Results of a phase I clinical study using autologous tumour lysate-pulsed monocyte-derived mature dendritic cell vaccinations for stage IV malignant melanoma patients combined with low dose interleukin-2. Melanoma Res 13: 521-530, 2003.

17. Hersey P, Menzies SW, Halliday GM, Nguyen T, Farrelly ML, DeSilva $C$ and Lett M: Phase I/II study of treatment with dendritic cell vaccines in patients with disseminated melanoma. Cancer Immunol Immunother 53: 125-134, 2004.

18. Jouanneau E, Poujol D, Gulia S, Le Mercier I, Blay JY, Belin MF and Puisieux I: Dendritic cells are essential for priming but inefficient for boosting antitumour immune response in an orthotopic murine glioma model. Cancer Immunol Immunother 55: 254-267, 2006

19. Zhang Y, Yoneyama H, Wang Y, Ishikawa S, Hashimoto S, Gao JL, Murphy P and Matsushima K: Mobilization of dendritic cell precursors into the circulation by administration of MIP-1alpha in mice. J Natl Cancer Inst 96: 201-209, 2004.
20. Hatfield P, Merrick AE, West E, O'Donnell D, Selby P, Vile R and Melcher AA: Optimization of dendritic cell loading with tumor cell lysates for cancer immunotherapy. J Immunother 31: 620-632, 2008.

21. Kim HS, Choo YS, Koo T, Bang S, Oh TY, Wen J and Song SY: Enhancement of antitumor immunity of dendritic cells pulsed with heat-treated tumor lysate in murine pancreatic cancer. Immunol Lett 103: 142-148, 2006.

22. Qiu J, Li GW, Sui YF, Song HP, Si SY and Ge W: Heat-shocked tumor cell lysate-pulsed dendritic cells induce effective anti-tumor immune response in vivo. World J Gastroenterol 12: 473-478, 2006

23. Castelli C, Rivoltini L, Rini F, Belli F, Testori A, Maio M, Mazzaferro V, Coppa J, Srivastava PK and Parmiani G: Heat shock proteins: Biological functions and clinical application as personalized vaccines for human cancer. Cancer Immunol Immunother 53: 227-233, 2004.

24. Pelleitier M and Montplaisir S: The nude mouse: A model of deficient T-cell function. Methods Achiev Exp Pathol 7: 149-166, 1975.

25. Alberts B, Johnson A and Lewis J: Helper T cells and lymphocyte activation. In: Molecular Biology of the Cell. pp1-8, 2002.

26. Zhang Y, Zhang N, Zhao M and Hoffman RM: Comparison of the selective targeting efficacy of Salmonella typhimurium A1-R and VNP20009 on the Lewis lung carcinoma in nude mice. Oncotarget 6: 14625-14631, 2015.

27. Fu Q, Wu Y, Yan F, Wang N, Wang W, Cao X, Wang Y and Wan T: Efficient induction of a Her2-specific anti-tumor response by dendritic cells pulsed with a Hsp70L1-Her2 341-456 fusion protein. Cell Mol Immunol 8: 424-432, 2011.

28. Song S, Zhang K, You H, Wang J, Wang Z, Yan C and Liu F: Significant anti-tumour activity of adoptively transferred $\mathrm{T}$ cells elicited by intratumoral dendritic cell vaccine injection through enhancing the ratio of $\mathrm{CD}^{+} \mathrm{T}$ cell/regulatory $\mathrm{T}$ cells in tumour. Clin Exp Immunol 162: 75-83, 2010.

29. Piccioli D, Tavarini S, Borgogni E, Steri V, Nuti S, Sammicheli C, Bardelli M, Montagna D, Locatelli F and Wack A: Functional specialization of human circulating CD16 and CD1c myeloid dendritic-cell subsets. Blood 109: 5371-5379, 2007.

30. Audiger C, Rahman MJ, Yun TJ, Tarbell KV and Lesage S: The importance of dendritic cells in maintaining immune tolerance. J Immunol 198: 2223-2231, 2017.

31. Liu J, Cao S, Kim S, Chung EY, Homma Y, Guan X, Jimenez V and Ma X: Interleukin-12: An update on its immunological activities, signaling and regulation of gene expression. Curr Immunol Rev 1: 119-137, 2005.

32. Blanco P, Palucka AK, Pascual V and Banchereau J: Dendritic cells and cytokines in human inflammatory and autoimmune diseases. Cytokine Growth Factor Rev 19: 41-52, 2008.

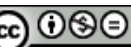

This work is licensed under a Creative Commons Attribution-NonCommercial-NoDerivatives 4.0 International (CC BY-NC-ND 4.0) License. 